\title{
A Precision Medicine Approach to SARS-CoV-2 Pandemic Management
}

\author{
Carlos D. Crisci, $M D^{1, *}$ \\ Ledit R. F. Ardusso, MD \\ Antonela Mossuz, $M D^{3}$ \\ Leila Müller, $M D^{3}$
}

\author{
Address \\ ${ }^{*}, 1$ Department of Pulmonology, Allergy and Immunology, National University of \\ Rosario School of Medicine, Santa Fe 3100, 2000, Rosario, Argentina \\ Email: carlosdcrisci@gmail.com \\ ${ }^{2}$ Allergy and Immunology, National University of Rosario School of Medicine, \\ Rosario, Argentina \\ ${ }^{3}$ Allergy and Immunology Department, Hospital Centenario, Rosario, Argentina
}

Published online: 8 May 2020

(C) Springer Nature Switzerland AG 2020

Keywords Precision medicine · COVID-19 • Biomarkers · Coronavirus management algorithm

\begin{abstract}
Purpose of review Precision medicine (PM) represents a new paradigm in disease diagnosis, prevention, and treatment. To apply PM premises in an emerging coronavirus pandemic acquires potentially greater relevance in order to allow the selection of specific preventive measures as well as biomarkers that will be useful in disease management.

Recent findings The identification of the new coronavirus severe acute respiratory syndrome coronavirus 2 (SARS-CoV-2) as the responsible for the coronavirus disease 2019 (COVID-19) pandemic had led to a plethora of strategies to contain viral dissemination, affecting life styles and personal behaviors. Viral genomic sequencing has shown that SARS-CoV-2 spike protein utilizes angiotensin-converting enzyme 2 (ACE2) found on ciliated epithelial cells of the human lungs as its specific receptor. Neutralizing antibodies to the receptor-binding domain of the spike protein were detected in patients recovered from COVID-19; however, both T cells and NK cells were reduced in severe cases. Excessive and uncontrolled releases of pro-inflammatory cytokines such as IL-1B, IL-1RA, IL-7, IL-8, IL-9, IL-10, fibroblast growth factor (FGF), granulocyte-macrophage colony-stimulating factor (GM-CSF), and tumor necrosis factor (TNFa) were increased in severe patients. These cytokines might be useful biomarkers of disease worsening and potential targets for new biological therapies currently under investigation.

Summary Present knowledge and recent developments in PM approach to COVID-19 disease prevention, evaluation, and management are pointed out. Better understanding of pathogenic pathways together with an accurate phenotype classification of patients
\end{abstract}


presented with SARS-CoV-2 infection and symptoms might contribute to a more accurate definition of biomarkers and other diagnostic tools, which may lead to more precise mitigation strategies, personalized pharmacologic options, as well as new biological therapy developments.

\section{Introduction}

Four coronaviruses are endemic worldwide causing common colds in humans. The viruses known as human coronavirus (hCoV)-229E, hCoV-HKU1, hCoV-NL63, and hCoV-OC43 are of little concern at a global public health level. Two other coronaviruses have caused significant epidemics of severe acute respiratory syndrome (SARS), one in China during 2002-2003 (SARS-CoV) and the other one confined to regions of the Middle East (MERS-CoV), emerging in 2012 and showing limited human-to-human transmission but a high case fatality ratio (CFR) [1]. At the end of 2019, a new coronavirus causing a severe acute respiratory symptom (SARS-CoV-2) emerged in China rapidly spreading around the world resulting in a new coronavirus disease termed coronavirus disease 2019 (COVID-19). After an initial lag phase, cases of COVID-19 followed an exponential curve and spread around the world affecting more than 1.8 million over 185 countries on Easter Day. Precision medicine (PM) is an emerging new paradigm in disease management $\left[2^{\circ}\right]$. PM develops on recent advances in omic sciences, molecular biology, and bioinformatics, applying them to the evaluation and treatment of health disorders.

This new approach goes beyond a medicine reactive to pain and disease, focusing on four essential premises $[2 \bullet \bullet]$ :

- Prediction, that is, to anticipate the appearance of diseases by acting on risk factors, lifestyle, and social determinants.

- Prevention, which implies proposing actions that can delay the evolution of the pathology before the first manifestations occur and carry out secondary prevention once the disease has settled.

- Personalization, analyzing the genetic, molecular, and particular factors of each individual and pathogen, recommending the best therapeutic strategy adapted to their condition.

- Participation, which requires the involvement of biomedical research, academic institutions, health professionals, and, above all, the patient himself.

Based on the knowledge of the pathophysiological mechanisms (endotypes) and the various clinical expressions (phenotypes) of a disease, PM seeks to identify the best management strategies that allow arriving to an accurate diagnosis, which in turn facilitates a predictive, preventive, and therapeutic approach adjusted to the characteristics and needs of the patient, promoting his or her active participation in decision-making.

The three steps of PM are as follows: (1) pathophysiology: identification of molecular mechanisms of the disease and its variants; (2) prediction/diagnosis: identification of biomarkers and specific diagnostic tools; and (3) management: blocking/interfere those mechanisms for prevention and/or treatment [3].

The World Health Organization (WHO) on March 11 declared COVID-19 a pandemic. In an emerging new coronavirus pandemic, which not only puts public health in crisis but also affects every sector and every individual, the application of PM premises acquires greater relevance. In this article, we will discuss present knowledge and emerging developments for each step in PM approach to COVID-19 evaluation and management.

\section{SARS-CoV-2 virology}

In late December 2019, Chinese health authorities reported the death of a patient suffering from viral pneumonia of unknown origin, which occurred in the populous city of Wuhan. A short-time late human-human transmission was suspected, and finally, the sequence of a new coronavirus as responsible for COVID-19 was reported [4]. 


\section{Clinical, laboratory, and imaging features of COVID-19}

The first performed systematic literature review with meta-analysis, using three databases to assess clinical, laboratory, imaging features, and outcomes of

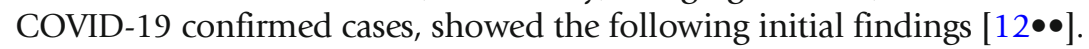

\section{Demographical characteristics and comorbidities}

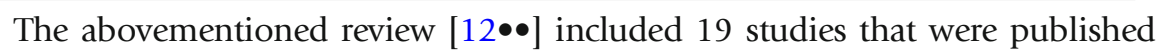
between January 1, 2020 and February 21, 2020, most of them from China.

The mean age of patients was close to 52 years, being $56 \%$ males. In $37 \%$ of cases, patients presented with comorbidities, the most significant being hypertension (18.6\%), cardiovascular disease (14.4\%), and diabetes (11.9\%), among others, such as chronic obstructive pulmonary disease (COPD) (1.8\%), chronic liver disease (3\%), and malignancies (2.5\%).

Fever (88.7\%), cough (57.6\%), and dyspnea (45.6\%) were the most prevalent clinical manifestations. Other reported symptoms included sore throat, myalgia and fatigue, headache, and diarrhea. Loss of smell and taste has been reported as one distinctive feature [13].

Among severe patients (20.3\%) who required ICU, 32.8\% presented with acute respiratory distress syndrome (ARDS), $13.0 \%$ with acute cardiac injury, $7.9 \%$ with acute kidney injury, $6.2 \%$ with shock, and $13.9 \%$ had fatal outcomes. 
Decreased albumin (76\%), high C-reactive protein (CRP) (58\%), high lactate dehydrogenase (LDH) $(57 \%)$, reduced lymphocyte counts $(43 \%)$, and high erythrocyte sedimentation rate (ESR) $(42 \%)$ were the most prevalent laboratory results. Creatinine, liver profile, and ferritin were also altered. D-dimer increased levels were reported to be associated with severity of COVID-19 disease [14].

Detection of viral RNA in blood was reported in $96.8 \%$ of all patients and also in nasopharyngeal aspirates (NPA). Elevated lactate dehydrogenase and ferritin levels are common, and elevated aminotransferase levels have also been described. On admission, many patients with pneumonia have normal serum procalcitonin levels; however, in those requiring ICU care, they are more likely to be elevated [15-17].

\section{Imaging}

Chest radiographs may be normal in early or mild disease. Common abnormal radiograph findings were consolidation and ground glass opacities $(68.5 \%)$, with bilateral (73\%), peripheral, and lower lung zone distributions. Lung involvement increased over the course of illness, with a peak in severity at 10 to 12 days after symptom onset.

Chest CT in patients with COVID-19 most commonly demonstrates ground-glass opacification with or without consolidative abnormalities, consistent with viral pneumonia $[18 \bullet, 19]$. Case series have suggested that chest CT abnormalities are more likely to be bilateral, have a peripheral distribution, and involve the lower lobes. Less common findings include pleural thickening, pleural effusion, and lymphadenopathy.

In patients who did not develop severe respiratory distress, lung abnormalities on chest imaging were most severe approximately 10 days after symptom onset [20]. However, chest CT abnormalities have also been identified in patients prior to the development of symptoms and even prior to the detection of viral RNA from upper respiratory samples $[19,21]$. Among patients who clinically improve, resolution of radiographic abnormalities may lag behind improvements in fever and hypoxia [22].

\section{Immunity}

In patients recovered from COVID-19, antibodies to the receptor-binding domain of the spike protein and the nucleocapsid protein were detected by enzyme-linked immunosorbent assay (ELISA) 14 days following the onset of symptoms; ELISA antibody titers correlated with neutralizing activity [23]. One preliminary study reported that rhesus macaques infected with SARS-CoV-2 did not develop reinfection following recovery and re-challenge [24]; however, this study has not been published in a peer-reviewed journal, and further confirmation of these findings is needed.

US Food and Drug Administration (FDA) has approved a test that qualitatively identifies immunoglobulin (Ig)M and IgG antibodies against SARS-CoV-2 in serum or plasma [25]. Serologic screening is an important tool to understand population immunity and distinguish individuals who are at lower risk for reinfection. 
Lymphocytopenia is one of the most prominent markers of COVID-19 [26]. Both T cells and NK cells in patients with COVID-19 are reduced, and such reduction correlates with disease severity, as is the case of memory helper T cells and regulatory T cells $[27 \bullet, 28]$.

Autopsy findings usually reveal spleen atrophy, significant cell degeneration, focal hemorrhagic necrosis, macrophage proliferation, and macrophage phagocytosis. The number of lymph nodes is concomitantly reduced, showing atrophy and necrosis. Immunohistochemical staining showed that $\mathrm{CD} 4^{+} \mathrm{T}$ cells and $\mathrm{CD}^{+} \mathrm{T}$ cells were decreased in the spleen and lymph nodes [27•]. The major infiltrated cells in the lung are monocytes and macrophages, whereas the number of lymphocytes is very few, with the lung showing a characteristic bilateral diffuse alveolar injury with cellular fibromyxoid exudates. Most of the infiltrating lymphocytes are CD4-positive T cells. Furthermore, virus inclusion bodies can still be detected in type II alveolar epithelia and macrophages, despite a PCR-negative test $[28,29 \bullet, 30]$.

Those findings do not seem to be related to a hyper cytokine secretion induced by activated T cells in a late stage of viral infection. Rather, it is more characteristic of a secondary release of a great amount of cytokines and chemokines by alveolar macrophages, epithelial cells, and endothelial cells, as a result of the viral infection $[31 \bullet \bullet, 32]$.

Zhang $\mathrm{W}$ et al. [28] proposed two possible reasons for the destruction of the immune system in patients with COVID-19: lymphocytes directly invaded by virus or indirectly damaged by the cytokine storm (CS). As it is known that SARS-CoV-2 infects target cells through ACE2, while there was no ACE2 expression on lymphocytes, it is speculated that lymphocytes were probably destroyed by CS [28].

\section{Pathology}

Peripheral flow cytometry commonly shows decreased CD4 and CD8 cell counts, but an increase in Th17 cell proportion [29•]. Th17 cells are helper T cells differentiated from Th0 cells mainly stimulated by IL-6 and IL-23 [33]. Inflammatory cytokines like IL-6, IL-10, IL-2, and IFN $\gamma$ increased in severe cases.

As summarized by Zhang $\mathrm{C}$ et al. [34], the pathological mechanism of the pulmonary disease starts when SARS-CoV-2 infects alveolar epithelial cells (mainly alveolar epithelial type 2 cells [AEC2]) through the ACE2 receptor. The destruction of epithelial cells and the increase of cell permeability lead to the release of the virus. SARS-CoV-2 activates the innate immune system; macrophages and other innate immune cells not only capture the virus but also release a large number of cytokines and chemokines. Adaptive immunity is also activated by antigen-presenting cells (mainly dendritic cells). T and B cells not only play an antiviral role but also directly or indirectly promote the secretion of inflammatory cytokines. In addition, under the stimulation of inflammatory factors, a large number of inflammatory exudates and erythrocytes enter the alveoli, resulting in dyspnea and respiratory failure [34].

Endothelium damage is another prominent pathological manifestation in severe COVID-19 patients. Clinically, many critical ill patients have vasculitislike manifestations or even gangrene at their extremities [28]. 
Pathology examination of the lung reveals the blood vessels of alveolar septum were congested and edematous, with modest monocyte infiltration within and around blood vessels. Small vessels show hyperplasia, vessel wall thickening, lumen stenosis, occlusion, and focal hemorrhage. Hyaline thrombi of microvessels were found in a proportion of severe cases $[27,29 \bullet, 30]$. The underlying mechanism of vascular damage may be due to the direct injury of endothelial cells either by virus, leading to disseminated intravascular coagulation (DIC), or by an antiphospholipid syndrome (APS) as antiphospholipid, anticardiolipin, and anti- $\beta 2$ glycoprotein antibodies have been observed and associated with severe thrombosis in some patients [28].

\section{Biomarkers}

Cytokine storm (CS) refers to an excessive and uncontrolled release of pro-inflammatory cytokines. In infectious diseases, CS usually originates from the focal infected area, spreading through circulation. Huang et al. [15] measured cytokine levels in 41 inpatients (including 13 ICU patients and 28 non ICU patients). IL-1B, IL-1RA, IL-7, IL-8, IL-9, IL-10, fibroblast growth factor (FGF), granulocyte-macrophage colonystimulating factor (GM-CSF), IFN $\gamma$, granulocyte-colony stimulating factor (G-CSF), interferon- $\gamma$-inducible protein (IP10), monocyte chemoattractant protein (MCP1), macrophage inflammatory protein 1 alpha (MIP1A), platelet-derived growth factor (PDGF), tumor necrosis factor $(\mathrm{TNF} \alpha)$, and vascular endothelial growth factor (VEGF) were increased. Several chemokines (CCL2, CCL3, CCL5, CXCL8, CXCL9, CXCL10) were also find to be higher in severe patients $[15,35,36]$. Many other reports also confirmed the elevation of IL- 6 in critically ill patients with COVID-19 [35, 37, 38, 39•].

One other study $\left[39^{\circ}\right]$ analyzed the lymphocyte subsets and cytokines in 123 patients. All patients had lymphocytopenia; the percentage of CD8 cells and the NK cells showed higher reduction in severe groups when compared to mild patients. However, the expression of HLA-DR (a marker of lymphocyte activation), in $\mathrm{CD}^{+}$and $\mathrm{CD}^{+}$cells, as well as in Th17 cells, was also shown to be increased, and the cytotoxic particles such as perforin and granulysin were highly expressed in $\mathrm{CD}^{+} \mathrm{T}$ cells [39•].

Considering all the abovementioned features of the COVID-19 illness, Siddiqu and Mehra [40] proposed a 3-stage classification model recognizing that increasing severity corresponds with distinct clinical findings, imaging, and biochemistry characteristics and clinical outcome. The initial stage occurs at the time of inoculation and early establishment of disease. This involves an incubation period associated with fever and mild respiratory symptoms. Diagnosis at this stage includes PCR for SARS-CoV-2. Blood count may reveal a lymphopenia and neutrophilia without other significant abnormalities. In the second stage, viral multiplication and localized inflammation in the lung are the norm. During this stage, patients develop a viral pneumonia and possibly hypoxia. Imaging reveals bilateral infiltrates or ground glass opacities. The third and most sever stage of illness manifested as an extra-pulmonary 
systemic hyperinflammation syndrome, characterized by extremely elevated levels of the abovementioned biomarkers of systemic inflammation [40].

\section{Precision medicine guided COVID-19 pandemic management}

Following the principles of precision medicine, the management of COVID-19 pandemic must anticipate the appearance of diseases by acting on risk factors, lifestyles, and social determinants (prediction); proposing actions that can delay the evolution of the pathology before the first manifestations occur and carry out secondary prevention once the disease has settled (prevention), analyzing the genetic, molecular, and particular factors of each individual and pathogen; recommending the best therapeutic strategy adapted to their condition (personalized); and requiring the involvement of biomedical research, academic institutions, health professionals, and, above all, the patient himself (participation).

\section{Preventive measures}

Primary prevention

According to the World Health Organization (WHO), main preventive actions should be directed to planning and coordinating sanitary strategies, monitoring and assessing the evolving pandemic and its impact, and implementing mitigation measures, including complete communication actions and efforts to reduce the speed of the disease and prepare, scale up, and guarantee continuity of health care provision [41].

A wide range of actions with different levels of strictness and firmness should be administered during de contention phase in order to prevent community circulation. These include the following: travel restrictions; border closures and/or incoming passenger restrictions; screening at airports and train and bus stations; cancelation of sporting, religious, and cultural events; and closing schools and universities. People should be advised about frequent hand washing, covering one's mouth when coughing, maintaining distance with other individuals, and environmental cleaning and disinfection.

Further actions devoted to reduce virus spread include quarantines, curfew measures, controlled repatriation, and isolation of travelers. During the mitigation phase, telemedicine may help to identify suspected cases performing pre-diagnosis triage through telehealth centralized phone lines and to control the movement of and monitoring evolution of infected people and their contacts through mobile applications for geo-localization.

In case of sustained community transmission, health authorities must guarantee the timely management of the emergency and the availability of enough health and logistic resources. 
Although the coronavirus pandemic is still ongoing around the world, preliminary observations seem to show that those countries that started stricter isolation measures earlier on could have a better evolution and would not seriously affect the capacity and effectiveness of their health system.

To end the isolation and quarantine, there are some necessary conditions that governments must have in order to return people to their normal activities. These include the following: specific measures to control virus transmission; guarantee the availability of public health and care; minimize the risk in exposed environments; apply prevention measures in jobs, schools, and places of public affluence; control the risk of imported cases; and promote the participation and responsibility of the population.

At present time, there is no known specific, effective, proven, pharmacological treatment to prevent or treat COVID-19. Current clinical management comprises control measures and supportive care, including supplemental oxygen and mechanical ventilatory support when indicated [42].

Due to the urgent need for drugs that serve to treat the infection and its various complications, in the last few months, numerous medications have been proposed based on their different pharmacological activities and previous experiences with other pathogens. Also because of this urgency, many clinical trials have been rapidly approved. Up to the 11th of April, we identified more than 400 clinical trials when searching in www.clinicaltrial.gob using the search terms COVID (242 studies), SARS-CoV-2 (135 studies), 2019-nCoV (38 studies), 2019 novel coronavirus (17 studies), and severe acute respiratory syndrome coronavirus (8 studies). Two hundred eighty of them are interventional studies classified into 33 categories of drugs interventions (Table 1). Most of them fall into one of two categories: (1) Treating respiratory symptoms, especially the inflammation that occurs in severe cases, and (2) antiviral growth, essentially stopping viruses from multiplying inside the human body. There are other outcomes such as to reduce organ failure and to treat pneumonia and/or sepsis, among others (Table 2).

Table 1. Drug interventions for COVID-19 sorted by pharmacological category

\begin{tabular}{lll}
\hline Analgesics & Blood substitutes & Lipid-regulating agents \\
Antiallergic agents & Bone density conservation agents & Micronutrients \\
Antiarrhythmia agents & Cardiotonic agents & Natriuretic agents \\
Antiinfective agents & Central nervous system depressants & Neuroprotective agents \\
Antiinflammatory agents & Channel blockers & Platelet aggregation inhibitors \\
Anticoagulants & Coagulants & Renal agents \\
Antiemetics & Dermatologic agents & Reproductive control agents \\
Antihypertensive agents & Fibrinolytic agents & Respiratory system agents \\
Antineoplastic agents & Gastrointestinal agents & Urological agents \\
Antipyretics & Hematinics & Vasoconstrictor agents \\
Antirheumatic agents & Hypoglycemic agents & Vasodilator agents
\end{tabular}


Table 2. Principal therapeutic interventions currently under investigation

\begin{tabular}{|c|c|c|}
\hline Treatment goal & Drug & Target \\
\hline \multirow[t]{4}{*}{ Anti-viral growth } & Ritonavir, prezcobix & - HIV protease Inhibitor \\
\hline & Remdesivir, favipiravir & - RNA polymerase inhibitors \\
\hline & Hydroxychloroquine & $\begin{array}{l}\text { - Not clearly known. Modify pH of endosomes and } \\
\text { prevents viral entry, transport and post-entry } \\
\text { events }\end{array}$ \\
\hline & Ivermectine & - Different anti-viral activity \\
\hline \multicolumn{3}{|l|}{ Anti-inflammatory } \\
\hline Interferon & IFNa inh, IFN $\beta 1 a$ & - IFNa inh, IFN $\beta 1 a$ \\
\hline Monoclonal antibodies & $\begin{array}{l}\text { Tocilizumab/sarilumab/siltuximab } \\
\text { Anakinra } \\
\text { Gimsilumab } \\
\text { Thalidomide }\end{array}$ & $\begin{array}{l}\text { - Anti-IL-6 } \\
\text { - Anti-IL-1 } \\
\text { - Anti-GM-GSF } \\
\text { - Anti-TNFa }\end{array}$ \\
\hline Anti gout & Colchicine & - Tubulin disruption \\
\hline Antibiotics & Azithromycin, clarithromycin & - Protease inhibitors (?) \\
\hline Reduce organ failure & Losartan & - RAAS inhibitor \\
\hline $\begin{array}{l}\text { Immune modulation } \\
\text { regeneration }\end{array}$ & Mesenchymal stem cells & \\
\hline \multirow[t]{3}{*}{ Pulmonary complications } & AiRuiKa & - PD-1 inhibitor \\
\hline & Avastin & - VEGF inhibitor \\
\hline & iNO/Sildenafil & - Pulmonary smooth muscle \\
\hline Passive immunity & Convalescent plasma & - Passive immunization \\
\hline Active immunity & Vaccines & - Anti-SARS-CoV-2 \\
\hline
\end{tabular}

In this article, we will briefly describe the most promising and cost/accessible drugs. The widespread use of several new antiviral drugs, as well as already marked monoclonal antibodies, becomes difficult due to their high cost and lack of availability. Precision medicine has to take into in account these issues.

\section{Antiviral growth therapy}

Patients with SARS-CoV-2 infection had the highest viral load (measured from posterior oropharyngeal saliva samples) close to when they presented [43]. The authors concluded that since viral load had already peaked around the time of hospital admissions, early use of potent antiviral agents might be beneficial in controlling COVID-19 severity. However, a standard treatment against SARSCoV-2 is presently lacking. The roles of several drugs including antiviral agents, some antibiotics, and antiinflammatory agents have been reviewed to explore their efficacy in combating the SARS-CoV-2 (data until April 10, 2020).

Remdesivir (GS-5734; Gilead Sciences Inc., Foster City, CA, USA) is an investigational intravenous drug with broad antiviral activity that 
inhibits viral replication through premature termination of RNA transcription and has in vitro activity against SARS-CoV-2 as well as in vivo activity against related betacoronaviruses. Unlike other nucleotide analogues, remdesivir is a phosphoramidate prodrug with broad-spectrum activity against many virus families, including Filoviridae, Paramyxoviridae, Pneumoviridae, and Orthocoronavirinae (such as pathogenic SARS-CoV and MERS-CoV) [44].

Favipiravir (Fujifilm Toyama Chemical Co. Ltd., Tokyo, Japan) is another RNA-dependent RNA polymerase inhibitor which is known to be active in vitro against oseltamivir-resistant influenza A, B, and C viruses [45].

Favipiravir was approved for the treatment of COVID-19 in China in March 2020. In addition, patients with COVID-19 infection are being recruited for randomized trials to evaluate the efficacy of favipiravir plus interferon- $\alpha$ (ChiCTR2000029600) and favipiravir plus baloxavir marboxil (ChiCTR2000029544).

\section{Antiparasitic compounds}

Hydroxychloroquine and chloroquine are oral prescription drugs that have been used for the treatment of malaria and certain inflammatory conditions. Mainly hydroxychloroquine is under investigation in clinical trials for pre-exposure or post-exposure prophylaxis of SARS-CoV-2 infection and treatment of patients with mild, moderate, and severe COVID-19 [46].

A recent systematic review concluded that evaluating the potentially favorable benefit-risk balance, without any choice of valid therapeutic options left, chloroquine and hydroxychloroquine could be applicable for the management of COVID-19 in the present context of outbreak; however, the respective national guidelines and clinician's evaluation and decision are recommended [47•].

Ivermectin is a widely available drug, due to its inclusion on the WHO model list of essential medicines, and is FDA-approved for parasitic infections. Ivermectin is an in vitro inhibitor of SARS-CoV-2 replication, a single treatment that is able to effect $\sim 5000$-fold reduction in virus at $48 \mathrm{~h}$ in cell culture [48].

\section{Antiinflammatory therapies}

As we mentioned above, in interferon, monoclonal antibodies, and small molecules such as Janus kinases (JAKs) and signal transducer and activator of transcription proteins (STATs), JAK-STAT signaling inhibitors appear to be effective as antiinflammatory agents capable to be used in the future to treat COVID-19. However, cost may be a concern. On the contrary, antigout drug colchicine and macrolides, such as azithromycin, could be a cheaper alternative.

Colchicine is an inexpensive medication that has been in use in the USA since 1969. This drug has antiinflammatory effect on gout and reduces attacks in familial Mediterranean fever in a phase 3 clinical trial [49].

Macrolides such as erythromycin, clarithromycin, and azithromycin not only have antibacterial activity but also have immunomodulatory effects, including antiinflammatory effects. Lately, the antiviral effects of macrolides have attracted considerable attention [50]. 
In an open-label, nonrandomized clinical trial using hydroxychloroquine and azithromycin for COVID-19 treatment, all 6 patients receiving combination therapy exhibited virological cure. In comparison, only $57.1 \%$ of the patients treated with hydroxychloroquine as a single drug and $12.5 \%$ in the control group exhibited virological cure $(P<0.001)$. Furthermore, one patient, who was treated with hydroxychloroquine as a single drug and still PCR-positive at day 6 , received azithromycin, resulting in virological cure. The authors propose that hydroxychloroquine in combination with azithromycin treatment might be an efficient antiviral therapy for COVID-19 [46].

\section{Glucocorticosteroids}

\section{Reduce organ failure therapy}

Current management of COVID-19 is supportive. ARDS is the leading cause of mortality [51]. Secondary hemophagocytic lymphohistiocytosis (sHLH) is an under-recognized, hyperinflammatory syndrome characterized by a fulminant and fatal hypercytokinemia with multiorgan failure [52].

The cytokine storm will trigger a violent attack by the immune system to the body, cause ARDS and multiple organ failure, and finally lead to death in severe cases of SARS-CoV-2 infection, just like what occurs in SARS-CoV and MERS$\mathrm{CoV}$ infections [29・].

Corticosteroids have the ability to inhibit cytokines and chemokines release and therefore to modulate inflammatory response. There are positive outcomes for the use of corticosteroids, particularly with reference to the SARS-CoV outbreak where they were widely used [53]. Various studies in humans noted that corticosteroids appeared effective in reducing immunopathological damage, but concerns centered on the possible promotion of viral rebound and association with adverse events (including ARDS).

In summary, till now, there are no reliable studies that have evaluated the efficacy and safety of corticosteroids in patients with COVID-19. Available data from studies in patients affected by other viral infections are conflicting and in some cases subject to multiple biases, although many note that treatment may produce various unwanted effects in patients.

Despite these data, some scientific societies have defined situations in which to use corticosteroid treatment to alleviate the uncontrolled inflammatory response caused by the virus, although in no case is there unanimity in their proposals.

The mechanism for SARS-CoV-2 infection starts with the binding of the virus spike to the membrane-bound form of angiotensin-converting enzyme 2 (ACE2) and internalization of the complex by the host cell [54]. ACE2 is an enzyme that physiologically counters renin-angiotensin-aldosterone system (RAAS) activation [55].

The interaction between the SARS viruses and ACE2 has been proposed as a potential factor in their infectivity, and there are concerns about the use of RAAS inhibitors that may alter ACE2 and whether variation in ACE2 expression may be in part responsible for disease virulence in the ongoing COVID-19 pandemic $[56,57]$. Clinical trials are under way to test the safety and efficacy of RAAS modulators, including recombinant human ACE2 (n016) $[58,59]$. 
Abrupt withdrawal of RAAS inhibitors in high-risk patients, including those who have heart failure or have had myocardial infarction, may result in clinical instability and adverse health outcomes. Until further data are available, RAAS inhibitors should be continued in patients in otherwise stable condition who are at risk for, being evaluated for, or with COVID-19 [56, 57, 60-63].

The uncertain effects of RAAS blockers on ACE2 levels and activity in humans has led to an alternative hypothesis that ACE2 may be beneficial rather than harmful in patients with lung injury. Furthermore, this hypothesis raises the concern that withdrawal of RAAS inhibitors may be harmful in certain high-risk patients with known or suspected COVID-19 [64].

\section{Passive immunity}

Convalescent plasma is the liquid part of blood that is collected from patients who have recovered from an infection. Antibodies present in convalescent plasma might help fight the infection.

This strategy was implemented half a century ago in Argentina to decrease the mortality from Argentine hemorrhagic fever caused by the Junín virus from 30 to 3\% [65]. Experience from prior outbreaks with other coronaviruses, such as SARS-CoV, showed that such convalescent sera contain neutralizing antibodies to the relevant virus [66]. This viewpoint argues human convalescent serum is an option for prevention and treatment of COVID-19 disease that could be rapidly available when there are sufficient numbers of people who have recovered and can donate immunoglobulin-containing serum [67].

Ongoing protocols of such passive immunization strategies are in recruitment phase around the world. The US FDA approved the use of plasma from recovered patients to treat people who are critically ill with COVID-19, provided that doctors get approval over the telephone.

\section{Vaccines}

Creating a safe vaccine for a new illness is no easy feat. Thankfully, rapid progress is being made for a variety of reasons, including efforts to sequence the genetic material of SARS-CoV-2 and to share that information among research groups around the world.

After the emergence of SARS-CoV-2, around 15 potential vaccine candidates are being developed worldwide [68]. Such vaccines are based on various technologies, including the administration of mRNA from viral surface proteins, gene vaccines, nanoparticles, and synthetic vaccines to subunits and to modified viruses [69].

One of the most promising leads on a COVID-19 vaccine is mRNA1273. This vaccine, developed by Moderna Therapeutics, is being developed with extreme urgency, skipping straight into human trials before it was even tested in animals. This method of vaccination uses a fragment of a pathogen, typically a surface protein, to trigger an immune response, teaching the body's immune system how to fight off the disease without actually introducing live pathogens. 


\section{BCG vaccination}

Another interesting strategy is the one proposed by Aaron $\mathrm{M}$ et al. [70•]. They argue that as the impact of the COVID-19 differed among countries, these differences not only could be attributed to differences in cultural norms, mitigation efforts, and health infrastructure. They propose that national differences in COVID-19 impact could be partially explained by the different national policies respect to Bacillus Calmette-Guerin (BCG) childhood vaccination. BCG vaccination has been reported to offer broad protection to respiratory infections. Countries without universal policies of BCG vaccination (Italy, the Netherlands, the USA) have been more severely affected than countries with universal and long-standing BCG policies. Countries that have a late start of universal BCG policy (Iran, 1984) had high mortality, consistent with the idea that BCG protects the vaccinated elderly population. BCG vaccination also reduced the number of reported COVID-19 cases in a country. The combination of reduced morbidity and mortality suggests that BCG vaccination might be a potential new tool in the fight against COVID-19.

\section{Emerging doubts and targets regarding treatment}

As we mentioned above, one of the main pathophysiologic mechanisms of the severe form of COVID-19 is the cytokine storm due mainly to macrophages activation. Other proposed mechanism is the pathological activation of thrombin, with multiple thrombotic episodes ranging from peripheral ischemia, pulmonary thromboembolism to disseminated intravascular coagulation. The first mechanism resembles the macrophage activation syndrome and, the second, the antiphospholipid syndrome.

Serum ferritin is associated with severe disease and correlates with the inflammatory reaction [71] as well as high D-dimer and a decreased in platelets counts, with the abnormal activation of coagulation cascade. Taking those concepts, some authors propose the use of glucocorticoid pulses [72•] if the patients presents high levels of ferritin and/or low molecular weight heparin when there are high levels of D-dimer [73•].

These concepts have important economic implications since corticosteroids and heparin are clearly significantly cheaper than any immunomodulatory monoclonal antibodies.

Another concern is that some authors believe that COVID-19 targets and infects erythrocytes instead of lung cells; basically, they think that it is not a viral pneumonia.

SARS-CoV-2 might affect the hemoglobin molecules in the blood and that is why severe hypoxemia and multiorgan failure develop due to a severe decrease in $\mathrm{Hb}$ carrying capacity caused by binding and inhibiting the heme molecule of the globin. It has been speculated that hydroxychloroquine and favipiravir work through inhibiting the attachment of the virus coat protein to the porphyrin ring molecule.

Also, ventilations and ARDS protocols might lead to ventilator-induced lung injury rather than treating the condition. In the same way, infiltrates on the Xray and CT scan might be caused by oxidative stress of the accumulation of the heme extracted by the virus in the alveoli causing chemical pneumonitis, not viral pneumonia. Alterations on hemoglobin metabolism are induced by SARS- 
CoV-2, and its dependence on porphyrin might explain why COVID-19 is more severe in men, diabetics, and older patients. The virus induces a condition similar to high altitude, methemoglobinemia, and carbon monoxide poisoning [74]. This theory could explain why mechanical ventilation is not so much effective in the treatment of ARDS. Actually, it could be futile and causing more lung damage, but much more evidence will be needed to sustain any change in therapeutic attitude.

Finally, from a prophylactic point of view, the use of bacterial lysates and other immune modulators has been proposed because of their well-known ability to restore the immune response in certain clinical conditions. They might stimulate the immune response to vaccination, especially in at risk populations [75-77]. The preventive administration of such immune modulators would facilitate the immune response against SARS-CoV-2 in persons and health professionals early exposed to the virus.

\section{Conclusion}

The COVID-19 pandemic has generated deep concern in the world for being an unknown pathogen, for the lack of a specific treatment and for having put at serious risk of exceeding the capabilities of the health systems.

PM implies the incorporation of a wide array of community and individual data, including clinical, lifestyle, genetic, and further biomarker information. It focuses on the stratification of patients, identifying modifiable traits that can be treated in a better way because of more precise and validated phenotypic recognition or due to a better understanding of the critical causal pathways.

The COVID-19 pandemic has created the opportunity to test the advantages of the precision medicine paradigm for preventive, diagnostic, and therapeutic management of a new challenge for public health.

A PM approach to COVID-19 pandemic management is schematically summarized in Fig. 1.

Roughly, three steps can be distinguished that goes from the logistical preparation of the health system before the contagions appear in the local population, passing through the suspicion and confirmation of the first cases and ending with treatment strategies according to the three stages in which the disease progress can be categorized.

Following the four "Ps" that characterize PM approach to disease management, in the first step, containment strategy is to prevent viral circulation in the population. Once it has occurred, in the second step, mitigation strategies must be capable to predict suspicious cases, confirm diagnosis, and isolate patients and their contacts in order to reduce the spread of the disease, as well as prepare and guarantee health care provision. Clinical symptoms, a history of potential exposure to SARS-Cov-2, and relevant comorbidities have to be inquired by centralized communication facilities in order to perform pre-diagnosis triage. The third step initiates with the final confirmation through a positive RT-PCR SARS-Cov-2 assay performed on nasopharyngeal aspirates. In mild cases, patients will only receive at home palliative treatment.

However, in the first stage of the disease, more symptomatic or at risk patients would require hospitalization, initial imaging, and laboratory tests. Therapeutic strategies in such cases focus in reducing viral replication and to 


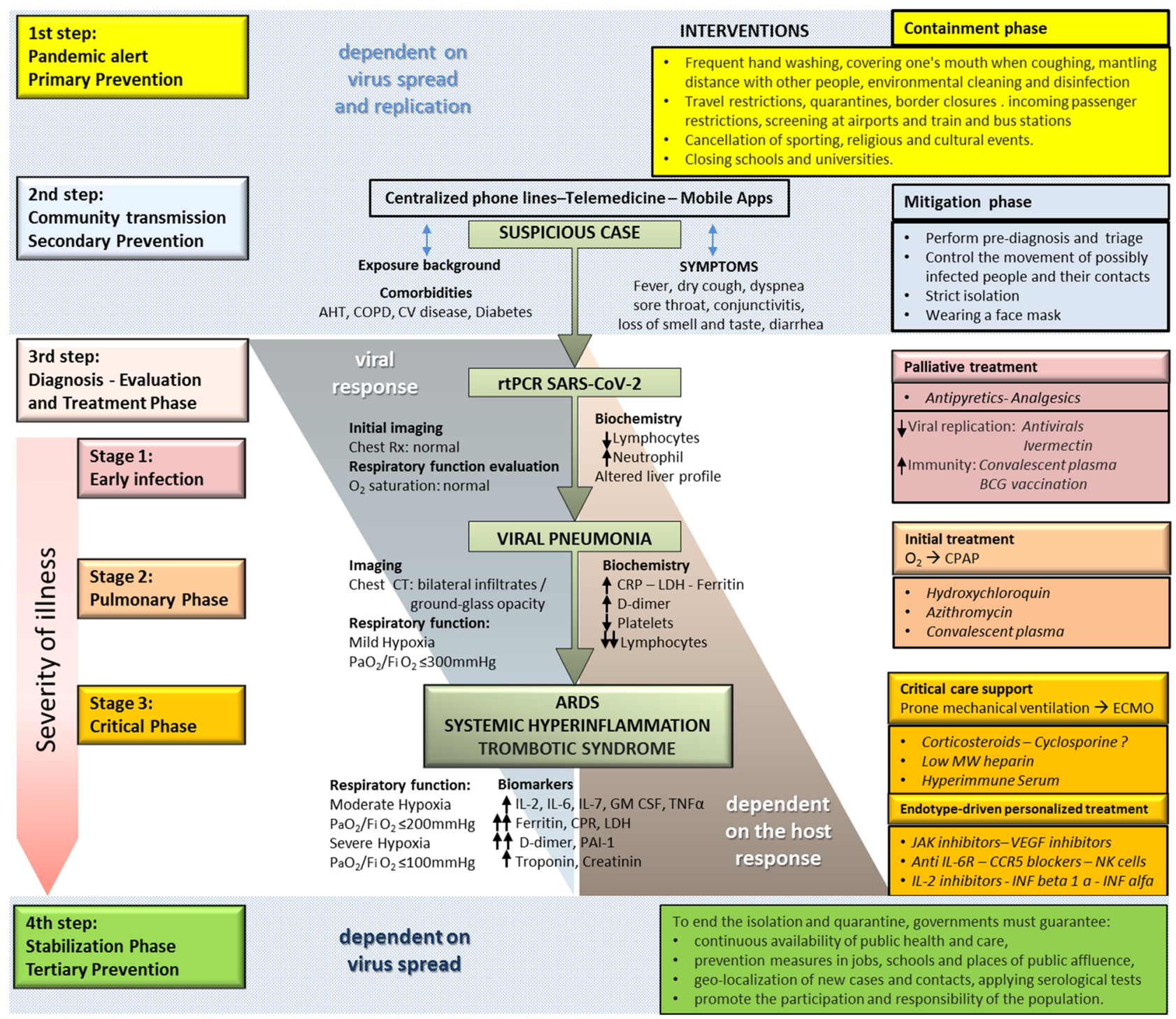

Fig. 1. A precision medicine approach to SARS-CoV-2 pandemic management. Following Siddiqu and Mehra [41], they proposed a 3stage classification model for COVID-19 illness. COPD chronic obstructive pulmonary disease, AHT arterial hypertension, CV disease cardiovascular disease, CRP C-reactive protein, $L D H$ lactate dehydrogenase, CPAP continuous positive airway pressure, ECMO extracorporeal membrane oxygenation, Low MW heparin low molecular weight heparin, $P A I$-1 plasminogen activator inhibitor $1, I L$ interleukin, GM-CSF granulocyte-macrophage colony-stimulating factor, MIP macrophage inflammatory protein, TNF tumor necrosis factor, JAK Janus kinase.

passively enhance immunity. When disease progresses into a second stage characterized by a viral pneumonia, the initial treatment might include a combination of antimalaria and macrolide antibiotics as well as antiinflammatory medications. Finally, the severely ill patient may present with systemic hyperinflammation, disseminated intravascular coagulation, and acute respiratory distress syndrome, requiring mechanical ventilation and supportive measures in a critical care unit. In this third stage of the disease, the evaluation of 
several specific biomarkers would allow the administration of personalized endotype-driven treatment.

The PM strategy for the COVID-19 pandemic would neither be complete nor could it be successfully undertaken without the participatory commitment of scientific advisory committees, the timely and firm management by health authorities, the collaboration of basic and clinical researchers, and the involvement of the pharmaceutical industry and government financial support.

\section{Acknowledgments}

The authors would like to thank Enrique Fernández Caldas from Madrid, Spain, for the final review of the manuscript.

\section{Compliance with Ethical Standards}

\section{Conflict of Interest}

Carlos Crisci declares that he has no conflict of interest. Ledit Ardusso declares that he has no conflict of interest. Antonela Mossuz declares that she has no conflict of interest. Leila Müller declares that she has no conflict of interest.

Human and Animal Rights and Informed Consent

This article does not contain any studies with human or animal subjects performed by any of the authors.

\section{References and Recommended Reading}

Papers of particular interest, published recently, have been highlighted as:

- Of importance

- Of major importance

1. de Wit E, van Doremalen N, Falzarano D, Munster VJ. SARS and MERS: recent insights into emerging coronaviruses. Nat Rev Microbiol. 2016;14:523-34.

2.• Sagner M, McNeil A, Puska P, Auffray C, Price ND, Hood L, et al. The P4 health spectrum - a predictive, preventive, personalized and participatory continuum for promoting healthspan. Prog Cardiovasc Dis. 2017;59:506-21

This is a necessary article to understand the four essential principles of PM.

3. Hamburg MA, Collins FS. The path to personalized medicine. N Engl J Med. 2010;363:301-4.

4. Gralinski LE, Menachery VD. Return of the coronavirus: 2019-nCoV. Viruses. 2020;12.

5. Zhou P, Yang X-L, Wang X-G, Hu B, Zhang L, Zhang W, et al. Discovery of a novel coronavirus associated with the recent pneumonia outbreak in humans and its potential bat origin. bioRxiv. Cold Spring Harb Lab; 2020a;2020.01.22.914952.
6. Li W, Moore MJ, Vasilieva N, Sui J, Wong SK, Berne MA, et al. Angiotensin-converting enzyme 2 is a functional receptor for the SARS coronavirus. Nature. 2003;426:450-4.

7. Liu Y, Gayle AA, Wilder-Smith A, Rocklöv J. The reproductive number of COVID-19 is higher compared to SARS coronavirus. J Travel Med. 2020;27.

8. WHO. Modes of transmission of virus causing COVID19: implications for IPC precaution recommendations [Internet]. who.int. 2020 [cited 2020 Aspr 13]. Available from: https://www.who.int/news-room/ commentaries/detail/modes-of-transmission-of-viruscausing-covid-19-implications-for-ipc-precautionrecommendations Menachery VD, Yount BL, Sims AC, Debbink K, Agnihothram SS, Gralinski LE, et al. SARS-like WIV1$\mathrm{CoV}$ poised for human emergence. Proc Natl Acad Sci U S A. 2016;113:3048-53.

10. Menachery VD, Yount BL, Debbink K, Agnihothram S, Gralinski LE, Plante JA, et al. A SARS-like cluster of 
circulating bat coronaviruses shows potential for human emergence. Nat Med. 2015;21:1508-13.

11. Ge X-Y, Li J-L, Yang X-L, Chmura AA, Zhu G, Epstein $\mathrm{JH}$, et al. Isolation and characterization of a bat SARSlike coronavirus that uses the ACE2 receptor. Nature. 2013;503:535-8.

12.• Rodriguez-Morales AJ, Cardona-Ospina JA, GutiérrezOcampo E, Villamizar-Peña R, Holguin-Rivera Y, Escalera-Antezana JP, et al. Clinical, laboratory and imaging features of COVID-19: a systematic review and meta-analysis. Travel Med Infect Dis. 2020;101623

This is the first meta-analysis reviewing clinical and laboratory findings of COVID-19.

13. Lechien JR, Chiesa-Estomba CM, De Siati DR, Horoi M, Le Bon SD, Rodriguez A, et al. Olfactory and gustatory dysfunctions as a clinical presentation of mild-tomoderate forms of the coronavirus disease (COVID19): a multicenter European study. Eur Arch Otorhinolaryngol [Internet]. 2020 [cited 2020 Apr 13]; Available from: https://doi.org/10.1007/s00405-02005965-1.

14. Lippi G, Favaloro EJ. D-dimer is associated with severity of coronavirus disease 2019: a pooled analysis. Thromb Haemost:2020.

15. Huang C, Wang Y, Li X, Ren L, Zhao J, Hu Y, Zhang L, Fan G, Xu J, Gu X, Cheng Z, Yu T, Xia J, Wei Y, Wu W, Xie X, Yin W, Li H, Liu M, Xiao Y, Gao H, Guo L, Xie J, Wang G, Jiang R, Gao Z, Jin Q, Wang J, Cao B Clinical features of patients infected with 2019 novel coronavirus in Wuhan, China. The Lancet. Elsevier; 2020;395:497-506

16. Wang D, Hu B, Hu C, Zhu F, Liu X, Zhang J, et al. Clinical characteristics of 138 hospitalized patients with 2019 novel coronavirus-infected pneumonia in Wuhan, China. JAMA. 2020.

17. Chen N, Zhou M, Dong X, Qu J, Gong F, Han Y, et al. Epidemiological and clinical characteristics of 99 cases of 2019 novel coronavirus pneumonia in Wuhan, China: a descriptive study. Lancet. 2020a;395:507-13.

18. Zhao W, Zhong Z, Xie X, Yu Q, Liu J. Relation between chest CT findings and clinical conditions of coronavirus disease (COVID-19) pneumonia: a multicenter study. AJR Am J Roentgenol. 2020:1-6

This is a multicenter analysis of chest CT findings and its relations to clinical evolution of COVID-19.

19. Shi H, Han X, Jiang N, Cao Y, Alwalid O, Gu J, Fan Y, Zheng $C$ Radiological findings from 81 patients with COVID-19 pneumonia in Wuhan, China: a descriptive study. Lancet Infect Dis. Elsevier; 2020a;20:425-434.

20. Pan F, Ye T, Sun P, Gui S, Liang B, Li L, et al. Time course of lung changes on chest CT during recovery from 2019 novel coronavirus (COVID-19) pneumonia. Radiology. 2020:200370.

21. Xie X, Zhong Z, Zhao W, Zheng C, Wang F, Liu J. Chest CT for typical 2019-nCoV pneumonia: relationship to negative RT-PCR testing. Radiology. Radiological Society of North America; 2020;200343.

22. Han X, Cao Y, Jiang N, Chen Y, Alwalid O, Zhang X, et al. Novel coronavirus pneumonia (COVID-19) progression course in 17 discharged patients: comparison of clinical and thin-section CT features during recovery. Clin Infect Dis. 2020.

23. To KK-W, Tsang OT-Y, Leung W-S, Tam AR, Wu T-C, Lung DC, et al. Temporal profiles of viral load in posterior oropharyngeal saliva samples and serum antibody responses during infection by SARS-CoV-2: an observational cohort study. The Lancet Infectious Diseases [Internet]. Elsevier; 2020a [cited 2020 Apr 11];0. Available from: https://www.thelancet.com/journals/ laninf/article/PIIS1473-3099(20)30196-1/abstract

24. Bao L, Deng W, Gao H, Xiao C, Liu J, Xue J, et al. Reinfection could not occur in SARS-CoV-2 infected rhesus macaques. bioRxiv. Cold Spring Harb Lab. 2020;2020(03):13.990226.

25. FDA. qSARS-CoV-2 IgG/IgM rapid test - letter of authorization [Internet]. US Food and Drug Administration; 2020 [cited 2020 Apr 11]. Available from: https:// www.fda.gov/media/136622/download

26. Tan L, Wang Q, Zhang D, Ding J, Huang Q, Tang Y-Q, et al. Lymphopenia predicts disease severity of COVID19: a descriptive and predictive study. medRxiv. Cold Spring Harbor Laboratory Press. 2020;2020(03):01.20029074.

27. Qin C, Zhou L, Hu Z, Zhang S, Yang S, Tao Y, et al. Dysregulation of immune response in patients with COVID-19 in Wuhan, China. Clin Infect Dis. 2020; Principal alterations in immune system response to SARSCoV-2 are described in this paper.

28. Zhang W, Zhao Y, Zhang F, Wang Q, Li T, Liu Z, et al. The use of anti-inflammatory drugs in the treatment of people with severe coronavirus disease 2019 (COVID19): the experience of clinical immunologists from China. Clin Immunol [Internet]. 2020a [cited 2020 Apr 11]; Available from: https://www.ncbi.nlm.nih. gov/pmc/articles/PMC7102614/

29. Xu Z, Shi L, Wang Y, Zhang J, Huang L, Zhang C, et al. Pathological findings of COVID-19 associated with acute respiratory distress syndrome. The Lancet Respiratory Medicine. Elsevier; 2020;8:420-2.

Principal pathological findings in COVID-19 are described in this paper.

30. Yao XH, Li TY, He ZC, Ping YF, Liu HW, Yu SC, et al. A pathological report of three COVID-19 cases by minimally invasive autopsies. Zhonghua Bing Li Xue Za Zhi. 2020;49:E009.

31.• Shimabukuro-Vornhagen A, Gödel P, Subklewe M, Stemmler HJ, Schlößer HA, Schlaak M, et al. Cytokine release syndrome. J Immunother Cancer. 2018;6:56

This article clearly describes what a cytokine storm is about.

32. Guo X-ZJ, Thomas PG. New fronts emerge in the influenza cytokine storm. Semin Immunopathol. 2017;39:541-50.

33. Miossec P, Kolls JK. Targeting IL-17 and TH17 cells in chronic inflammation. Nat Rev Drug Discov. 2012;11:763-76.

34. Zhang $\mathrm{C}, \mathrm{Wu} \mathrm{Z}$, Li J-W, Zhao H, Wang G-Q. The cytokine release syndrome (CRS) of severe COVID-19 and Interleukin-6 receptor (IL-6R) antagonist 
tocilizumab may be the key to reduce the mortality. Int J Antimicrob Agents. 2020b;105954.

35. Conti P, Ronconi G, Caraffa A, Gallenga C, Ross R, Frydas I, et al. Induction of pro-inflammatory cytokines (IL-1 and IL-6) and lung inflammation by Coronavirus-19 (COVI-19 or SARS-CoV-2): antiinflammatory strategies. J Biol Regul Homeost Agents. 2020;34.

36. Li X, Geng M, Peng Y, Meng L, Lu S. Molecular immune pathogenesis and diagnosis of COVID-19. Journal of Pharmaceutical Analysis [Internet]. 2020 [cited 2020 Apr 12]; Available from: http://www.sciencedirect. com/science/article/pii/S2095177920302045

37. Chen N, Zhou M, Dong X, Qu J, Gong F, Han Y, Qiu Y, Wang J, Liu Y, Wei Y, Xia J', Yu T, Zhang X, Zhang L Epidemiological and clinical characteristics of 99 cases of 2019 novel coronavirus pneumonia in Wuhan, China: a descriptive study. The Lancet. Elsevier; 2020b;395:507-513

38. Wu C, Chen X, Cai Y, Xia J, Zhou X, Xu S, et al. Risk factors associated with acute respiratory distress syndrome and death in patients with coronavirus disease 2019 pneumonia in Wuhan, China. JAMA Intern Med. 2020.

39.• Wan S, Yi Q, Fan S, Lv J, Zhang X, Guo L, et al. Characteristics of lymphocyte subsets and cytokines in peripheral blood of 123 hospitalized patients with 2019 novel coronavirus pneumonia (NCP). medRxiv. Cold Spring Harbor Laboratory Press; 2020;2020.02.10.20021832

This article summarized peripheral blood lymphocyte subpopulations and cytokine levels in COVID-19 hospitalized patients. This article clearly describes what a cytokine storm is about.

40. Siddiqi HK, Mehra MR. COVID-19 illness in native and immunosuppressed states: a clinical-therapeutic staging proposal. J Heart Lung Transplant [Internet]. 2020 [cited 2020 Apr 12]; Available from: https://www.ncbi. nlm.nih.gov/pmc/articles/PMC7118652/

41. Robinson J. Epidemics, pandemics, and outbreaks [Internet]. WebMD. 2020 [cited 2020 Apr 12]. Available from: https://www.webmd.com/cold-and-flu/whatare-epidemics-pandemics-outbreaks

42. e. Coronavirus disease 2019 (COVID-19) [Internet]. Centers for Disease Control and Prevention. 2020 [cited 2020 Apr 12]. Available from: https://www.cdc.gov/ coronavirus/2019-ncov/hcp/therapeutic-options.html

43. To KK-W, Tsang OT-Y, Leung W-S, Tam AR, Wu T-C, Lung DC, et al. Temporal profiles of viral load in posterior oropharyngeal saliva samples and serum antibody responses during infection by SARS-CoV-2: an observational cohort study. The Lancet Infectious Diseases [Internet]. Elsevier; 2020b [cited 2020 Apr 12];0. Available from: https://www.thelancet.com/journals/ laninf/article/PIIS1473-3099(20)30196-1/abstract

44. Sheahan TP, Sims AC, Graham RL, Menachery VD, Gralinski LE, Case JB, et al. Broad-spectrum antiviral GS-5734 inhibits both epidemic and zoonotic coronaviruses. Science Translational Medicine
[Internet]. American Association for the Advancement of Science; 2017 [cited 2020 Apr 12];9. Available from: https://stm.sciencemag.org/content/9/396/eaal3653

45. Wang Y, Fan G, Salam A, Horby P, Hayden FG, Chen C, et al. Comparative effectiveness of combined favipiravir and oseltamivir therapy versus oseltamivir monotherapy in critically ill patients with influenza virus infection. J Infect Dis [Internet]. 2019 [cited 2020a Apr 12]; Available from: https://academic.oup. com/jid/advance-article/doi/10.1093/infdis/jiz656/ 5673088

46. Gautret P, Lagier J-C, Parola P, Hoang VT, Meddeb L, Mailhe $\mathrm{M}$, et al. Hydroxychloroquine and azithromycin as a treatment of COVID-19: results of an open-label non-randomized clinical trial. Int J Antimicrob Agents. 2020;105949.

47. Rana DR, Dulal S. Therapeutic application of chloroquine and hydroxychloroquine in clinical trials for COVID-19: a systematic review. medRxiv. Cold Spring Harbor Laboratory Press; 2020;2020.03.22.20040964. This is a systematic review of the first published clinical trials on hydroxychloroquine for COVID-19 treatment. This article clearly describes what a cytokine storm is about.

48. Caly L, Druce JD, Catton MG, Jans DA, Wagstaff KM. The FDA-approved drug ivermectin inhibits the replication of SARS-CoV-2 in vitro. Antivir Res. 2020;104787.

49. Montreal Heart Institute. Colchicine Coronavirus SARS-CoV2 Trial (COLCORONA) [Internet]. ClinicalTrials.gov. 2020 [cited 2020 Apr 12]. Available from: https://clinicaltrials.gov/ct2/show/ NCT04322682

50. Min J-Y, Jang YJ. Macrolide therapy in respiratory viral infections. Mediat Inflamm. 2012;2012:649570.

51. Ruan Q, Yang K, Wang W, Jiang L, Song J. Clinical predictors of mortality due to COVID-19 based on an analysis of data of 150 patients from Wuhan, China. Intensive Care Med [Internet]. 2020 [cited 2020 Apr 12]; Available from: https://doi.org/10.1007/ s00134-020-05991-X.

52. Mehta P, McAuley DF, Brown M, Sanchez E, Tattersall RS, Manson JJ. COVID-19: consider cytokine storm syndromes and immunosuppression. The Lancet. Elsevier; 2020;395:1033-1034.

53. Russell B, Moss C, Rigg A, Hemelrijck MV. COVID-19 and treatment with NSAIDs and corticosteroids: should we be limiting their use in the clinical setting? ecancer [Internet]. 2020 [cited 2020 Apr 12]; Available from: http://ecancer.org/es/journal/article/1023-covid19-and-treatment-with-nsaids-and-corticosteroidsshould-we-be-limiting-their-use-in-the-clinical-setting

54. Hoffmann M, Kleine-Weber H, Schroeder S, Krüger N, Herrler T, Erichsen S, et al. SARS-CoV-2 cell entry depends on ACE2 and TMPRSS2 and is blocked by a clinically proven protease inhibitor. Cell. 2020;181:271-280.e8.

55. Wang W, McKinnie SMK, Farhan M, Paul M, McDonald T, McLean B, et al. Angiotensin-converting enzyme 2 metabolizes and partially inactivates Pyr- 
Apelin-13 and Apelin-17: physiological effects in the cardiovascular system. Hypertension. 2016;68:36577 .

56. Li W, Zhang C, Sui J, Kuhn JH, Moore MJ, Luo S, et al. Receptor and viral determinants of SARS-coronavirus adaptation to human ACE2. EMBO J. 2005;24:163443.

57. Wrapp D, Wang N, Corbett KS, Goldsmith JA, Hsieh CL, Abiona O, et al. Cryo-EM structure of the 2019-nCoV spike in the prefusion conformation. Science. 2020;367:1260-3.

58. Search of: losartan | COVID - list results [Internet]. ClinicalTrials.gov. [cited 2020 Apr 15]. Available from: https://clinicaltrials.gov/ct2/results?cond= COVID\&term $=$ losartan $\&$ cntry $=\&$ state $=\&$ city $=\&$ dist $=$ ).

59. Search of: ACE2 | COVID - list results [Internet]. ClinicalTrials.gov. [cited 2020 Apr 15]. Available from: https://clinicaltrials.gov/ct2/results?cond= COVID\&term $=$ ACE2 \& cntry $=\&$ state $=\&$ city $=\&$ dist $=) \%$ 20\%20and\%20the\%20ARB\%20losartan\%20in\% 20COVID-19\%20(n=7).

60. Fang L, Karakiulakis G, Roth M. Are patients with hypertension and diabetes mellitus at increased risk for COVID-19 infection? Lancet Respir Med. 2020;8:e21.

61. Watkins J. Preventing a covid-19 pandemic. BMJ. 2020;m810.

62. Esler M, Esler D. Can angiotensin receptor-blocking drugs perhaps be harmful in the COVID-19 pandemic? J Hypertens. 2020;38:781-2.

63. Diaz JH. Hypothesis: angiotensin-converting enzyme inhibitors and angiotensin receptor blockers may increase the risk of severe COVID-19. J Travel Med. 2020.

64. Vaduganathan M, Vardeny O, Michel T, McMurray JJV, Pfeffer MA, Solomon SD. Renin-angiotensin-

aldosterone system inhibitors in patients with Covid19. N Engl J Med. 2020;382:1653-9.

65. Maiztegui JI, Fernandez NJ, de Damilano AJ. Efficacy of immune plasma in treatment of Argentine haemorrhagic fever and association between treatment and a late neurological syndrome. Lancet. 1979;2:1216-7.

66. Zhang J-S, Chen J-T, Liu Y-X, Zhang Z-S, Gao H, Liu Y, et al. A serological survey on neutralizing antibody titer of SARS convalescent sera. J Med Virol. 2005;77:14750.

67. Casadevall A, Pirofski L. The convalescent sera option for containing COVID-19. J Clin Invest American Society for Clinical Investigation. 2020;130:1545-8.

68. Pang J, Wang MX, Ang IYH, Tan SHX, Lewis RF, Chen JI-P, et al. Potential rapid diagnostics, vaccine and therapeutics for 2019 novel coronavirus (2019-nCoV): a systematic review. J Clin Med 2020;9.

69. Lu S. Timely development of vaccines against SARSCoV-2. Emerging Microbes \& Infections Taylor \& Francis. 2020;9:542-4.

70. $\quad$ Miller A, Reandelar MJ, Fasciglione K, Roumenova V, Li Y, Otazu GH. Correlation between universal BCG vaccination policy and reduced morbidity and mortality for COVID-19: an epidemiological study. medRxiv. Cold Spring Harbor Laboratory Press; 2020;2020.03.24.20042937.

This article suggests that BCG vaccination could influence the epidemiology of the COVID-19.

71. Zhou F, Yu T, Du R, Fan G, Liu Y, Liu Z, et al. Clinical course and risk factors for mortality of adult inpatients with COVID-19 in Wuhan, China: a retrospective cohort study. The Lancet. Elsevier; 2020b;395:10541062.

72.• Wang Y, Jiang W, He Q, Wang C, Wang B, Zhou P, et al. Early, low-dose and short-term application of corticosteroid treatment in patients with severe COVID-19 pneumonia: single-center experience from Wuhan, China. medRxiv. Cold Spring Harbor Laboratory Press; 2020b;2020.03.06.20032342.

This article pointed out the utility of low-dose and short-term corticosteroids applications for COVID-19 treatment.

73.• Shi C, Wang C, Wang H, Yang C, Cai F, Zeng F, et al. The potential of low molecular weight heparin to mitigate cytokine storm in severe covid-19 patients: a retrospective clinical study. medRxiv. Cold Spring Harbor Laboratory Press; 2020b;2020.03.28.20046144.

This is a retrospective clinical study concerning the potential efficacy of anticoagulants to mitigate cytokine storm in COVID19 patients.

74. Wenzhong L, Hualan L. COVID-19: attacks the 1-beta chain of hemoglobin and captures the porphyrin to inhibit human heme metabolism. ChemRxiv [Internet]. ChemRxiv; 2020 [cited 2020 Apr 12]; Available from: https://chemrxiv.org/articles/COVID-19_ Disease_ORF8_and_Surface_Glycoprotein_Inhibit_ Heme_Metabolism_by_Binding_to_Porphyrin/ 11938173

75. Sánchez-Ramón S, Conejero L, Netea MG, Sancho D, Palomares Ó, Subiza JL. Trained immunity-based vaccines: a new paradigm for the development of broadspectrum anti-infectious formulations. Front Immunol. 2018;9:2936.

76. Maxwell KL. Bacterial twist to an antiviral defence. Nature. Nature Publishing Group; 2019;574:638-639. 77. Sly PD, Galbraith S, Islam Z, Holt B, Troy N, Holt PG. Primary prevention of severe lower respiratory illnesses in at-risk infants using the immunomodulator OM-85. J Allergy Clin Immunol. 2019;144:870-872.e11.

\section{Publisher's Note}

Springer Nature remains neutral with regard to jurisdictional claims in published maps and institutional affiliations. 